\title{
Intestinal a-glucosidase and some pancreatic enzymes inhibitory effect of hydroalcholic extract of Moringa stenopetala leaves
}

\author{
Alemayehu Toma ${ }^{1,2^{*}}$, Eyasu Makonnen ${ }^{1}$, Yelamtsehay Mekonnen ${ }^{3}$, Asfaw Debella ${ }^{4}$ and Sirichai Addisakwattana ${ }^{5}$
}

\begin{abstract}
Background: Moringa stenopetala has been used in traditional health systems to treat diabetes mellitus. One of the successful methods to prevent of the onset of diabetes is to control postprandial hyperglycemia by the inhibition of a-glucosidase and pancreatic a-amylase activities, resulting in the aggressive delay of the carbohydrate digestion of absorbable monosaccharides. The aim of the present study is to investigate the effect of the extract of the leaves of Moringa stenopetala on a-glucosidase, pancreatic a-amylase, pancreatic lipase, and pancreatic cholesterol esterase activities, and, therefore find out the relevance of the plant in controlling blood sugar and lipid levels.

Methods: The dried leaves of Moringa stenopetala were extracted with hydroalcoholic solvent and dried using rotary vapor under reduced pressure. The dried extracts were determined for the total phenolic compounds, flavonoid content and condensed tannins content by using Folin-Ciocateu's reagent, $\mathrm{AlCl}_{3}$ and vanillin assay, respectively. The dried extract of plant-based food was further quantified with respect to intestinal a-glucosidase (maltase and sucrase) inhibition and pancreatic a-amylase inhibition by glucose oxidase method and dinitrosalicylic (DNS) reagent, respectively.

Results: The phytochemical analysis indicated that flavonoid, total phenolic, and condensed tannin contents in the extract were $71.73 \pm 2.48 \mathrm{mg}$ quercetin equivalent $/ \mathrm{g}$ of crude extract, $79.81 \pm 2.85 \mathrm{mg}$ of gallic acid equivalent $/ \mathrm{g}$ of crude extract, $8.82 \pm 0.77 \mathrm{mg}$ catechin equivalent/g of crude extract, respectively. The extract inhibited intestinal sucrase more than intestinal maltase with $\mathrm{C}_{50}$ value of $1.47 \pm 0.19 \mathrm{mg} / \mathrm{ml}$. It also slightly inhibited pancreatic a-amylase, pancreatic lipase and pancreatic cholesterol esterase.

Conclusion: The result demonstrated the beneficial biochemical effects of Moringa stenopetala by inhibiting intestinal a-glucosidase, pancreatic cholesterol esterase and pancreatic lipase activities. A daily supplement intake of the leaves of Moringa stenopetala may help in reducing hyperglycemia and hyperlipidemia.
\end{abstract}

Keywords: Moringa stenopetala, Phytochemical analysis, a-glucosidase, Pancreatic enzymes

\section{Background}

Worldwide, the number of people with diabetes and pre-diabetes is exponentially increasing mainly due to aging, urbanization, unhealthy eating habits, increasing prevalence of obesity and lack of physical activity [1]. Diabetes mellitus is a leading cause of morbidity and mortality worldwide, with an estimated 382 million

\footnotetext{
* Correspondence: alemayehutoma@gmail.com

'Pharmacology Department, School of Medicine, Addis Ababa University, Addis Ababa, Ethiopia

${ }^{2}$ Pharmacology Unit, School of Medicine, Hawassa University, P O Box 1560, Hawassa, Ethiopia

Full list of author information is available at the end of the article
}

adults being affected and 5.1 million people killed in the year 2013. The prevalence is expected to be 592 million in the year 2035, with the greatest increases expected in low- and middle-income developing countries of the African, Asian, and South American regions. At present, $80 \%$ of the worlds' populations with diabetes live in low- and middle income countries [2]. Diabetes is also associated with a host of life threatening and potentially disabling macro- and micro-vascular complications [3]. Hence, there is a much larger burden in the form of loss of productivity as a result of restricted daily activity which results in high economic costs. 
Moringa stenopetala (Baker $f$ ) Cufodontis belongs to family Moringaceaeis commonly grown in Southern parts of Ethiopia [4]. The leaves of Moringa stenopetala are cooked and eaten as vegetables and the leaves and roots are used to treat malaria, diabetes, asthma, repelled placenta, hypertension and gastrointestinal problems [5,6]. It has been reported that Moringa stenopetala leaves and roots showed antitrypanosomal activity [7]. The antispasmodic effects of the leaves on smooth muscle tissues and antibiotic properties of the seeds $[5,8]$ have also been reported. The crude aqueous extract of the leaves demonstrated hypoglycemic activity [9]. The crude aqueous/ethanol extract and fractions of the leaves of Moringa stenopetala have been reported to have both hypoglycemic and antihyperglycemic effect [10,11]. Moreover, chronic administration of the n-butanol fraction of ethanol extract of Moringa stenopetala leaves in alloxan-induced diabetic mice showed antihyperglycemic and antihyperlipedimic effects with wide margins of safety, indicating its potential for long term management of diabetes [12].

The aim of the present study was to investigate the inhibitory effect of the leaf extract of Moringa stenopetala on $\alpha$-glucosidase, pancreatic $\alpha$-amylase, pancreatic lipase, and pancreatic cholesterol esterase activities besides phytochemical analysis.

\section{Methods}

\section{Chemicals}

Folin-Ciocalteu, quercetin, catechin, gallic acid, rat intestinal acetone powder, porcine pancreatic $\alpha$-amylase, vanillin, 3,5-dinitrosalicylic acid, glucose oxidase kits, p-nitrophenylbutylrate ( $\mathrm{p}-\mathrm{NPB}), \mathrm{p}$-nitrophenylpalmitate (p-NPP), taurodeoxycholic acid, taurocholic acid, porcine cholesterol esterase, porcine pancreatic lipase were purchased from Sigma-Aldrich Co. (St. Louis, MO, USA). All others chemicals used were of analytical grade.

\section{Collections and preparation of plant materials}

The leaves of Moringa stenopetala was collected from Gamo Gofa Zone, South Nation's Nationalities Peoples Region, 520 kilometer south of Addis Ababa. After collection, the plant was identified and authenticated by a taxonomist, and deposited in herbarium of Ethiopian nutrition and health research institute (ENHRI) with a voucher number AL-001. It was then dried under shade and crushed to powder for extraction.

\section{Preparation of plant material extract}

The powdered leaves $(1.2 \mathrm{Kg})$ were extracted by percolation using $70 \%(\mathrm{v} / \mathrm{v})$ ethanol, and the mixture was then filtered using Whatmann filter paper no. 1. The extract was dried by evaporation using rotary vaporizers under reduced pressure at a temperature of $40-45^{\circ} \mathrm{C}$.
The residue filtrate obtained was then dried by steam bath at $40^{\circ} \mathrm{C}$ and kept in refrigerator at $8^{\circ} \mathrm{C}$ for experimental usage. The yield of the extract was $20.1 \%$ in weight by weight $(\mathrm{w} / \mathrm{w})$.

\section{Determination of flavonoid content}

Estimation of flavonoid content in the dried extracts was done according to a previous method [13]. The dried extract $(0.5 \mathrm{mg})$ was dissolved in $80 \%$ ethanol $(1 \mathrm{ml})$. The sample solution $(50 \mu \mathrm{l})$ was added to $10 \mu \mathrm{l}$ of $\mathrm{AlCl}_{3}$ solution $(10 \% \mathrm{w} / \mathrm{v})$ and $10 \mu \mathrm{l}$ of $1 \mathrm{M}$ sodium acetate in absolute ethanol $(150 \mu \mathrm{l})$. After incubation at $30^{\circ} \mathrm{C}$ for $30 \mathrm{~min}$, the absorbance was measured immediately at $430 \mathrm{~nm}$. The estimation of flavonoid content was calculated from a calibration curve using quercetin as a standard. The results were expressed as milligram quercetin equivalent/gram dry weight of extract.

$$
\text { Flavonoid }(\mathrm{mg} / \mathrm{g})=\frac{(\text { Abs test sample-Abs blank)-Intercept }}{\text { Slope } \times \text { amount of sample in gram }}
$$

Where Abs test sample was the absorbance of extract with reagent, Abs blank was the absorbance of extract without reagent.

\section{Determination of total phenolic content}

Total phenolic content of the extract was performed according to a previous method [13]. The dried extract $(0.5 \mathrm{mg})$ was dissolved in distilled water $(1 \mathrm{ml})$. The sample solution $(50 \mu \mathrm{l})$ was mixed with $50 \mu \mathrm{l}$ of Folin-Ciocateu's reagent followed by $50 \mu \mathrm{l}$ of $\mathrm{Na}_{2} \mathrm{CO}_{3}(10 \% \mathrm{w} / \mathrm{v})$. After incubation at $30^{\circ} \mathrm{C}$ for $60 \mathrm{~min}$, the absorbance was measured at $760 \mathrm{~nm}$ using a microplate reader. Total phenolic content was calculated from a calibration curve using gallic acid as a standard. The results were expressed as milligram gallic acid equivalent/gram dry weight of extract.

$$
\begin{aligned}
& \text { Total phenolic compounds }(\mathrm{mg} / \mathrm{g}) \\
& =\frac{(\text { Abs test sample-Abs blank }) \text {-Intercept }}{\text { Slope } \times \text { amount of sample in gram }}
\end{aligned}
$$

Where Abs test sample was the absorbance of extract with reagent, Abs blank was the absorbance of extract without reagent.

\section{Determination of condensed tannin content}

Estimation of condensed tannin content in the dried extracts was done according to a previous method [14]. The dried extract (5 mg) was dissolved in $80 \%$ ethanol $(1 \mathrm{ml})$. The sample solution $(50 \mu \mathrm{l})$ was added to $100 \mu \mathrm{l}$ of vanillic acid solution ( $4 \% \mathrm{w} / \mathrm{v})$ and $50 \mu \mathrm{l}$ of concentrated $\mathrm{HCl}$. The absorbance was measured immediately at $500 \mathrm{~nm}$. The estimation of condensed tannin content was calculated from a calibration curve using catechin 
as a standard. The results were expressed as milligram catechin equivalent/gram dry weight of extract.

$$
\text { Condensed tannins }(\mathrm{mg} / \mathrm{g})=\frac{(\text { Abs test sample-Abs blank }) \text {-Intercept }}{\text { Slope } \times \text { amount of sample in gram }}
$$

Where Abs test sample was the absorbance of extract with reagent, Abs blank was the absorbance of extract without reagent.

\section{Pancreatic a-amylase inhibitory activity}

The pancreatic $\alpha$-amylase inhibition assay was performed according to a previous report [15]. Porcine pancreatic $\alpha$-amylase (3units $/ \mathrm{ml}$ ) was dissolved in $0.1 \mathrm{M}$ phosphate buffer saline, $\mathrm{pH}$ 6.9. The various concentrations of the extract $(10 \mu \mathrm{l})$ were added to a solution containing starch $(1 \mathrm{~g} / \mathrm{l})$ and phosphate buffer $(165 \mu \mathrm{l})$. The reaction was initiated by adding enzyme solution $(75 \mu \mathrm{l})$ to the incubation medium. After 10 min incubation, the reaction was stopped by adding $250 \mathrm{ml}$ dinitrosalicylic (DNS) reagent (1\% 3, 5-dinitrosalicylic acid, 0.2\% phenol, $0.05 \% \mathrm{Na}_{2} \mathrm{SO}_{3}$ and $1 \% \mathrm{NaOH}$ in aqueous solution) to the reaction mixture. The mixtures were heated at $100^{\circ} \mathrm{C}$ for $10 \mathrm{~min}$ in order to stop the reaction. Thereafter, $250 \mu \mathrm{l}$ of $40 \%$ potassium sodium tartarate solution was added to the mixtures to stabilize the color. After cooling to room temperature in a cold water bath, the absorbance was recorded at $540 \mathrm{~nm}$ using a microplate reader. Acrabose was used as positive control.

$$
\% \text { Inhibition }=\frac{\text { AbsContol-AbsSample } \times 100}{\text { AbsControl }}
$$

Where Abs Control was the absorbance without sample, Abs samples was the absorbance of sample extract.

\section{Intestinal a-glucosidase inhibitory activity}

The assessment of intestinal $\alpha$-glucosidase inhibitory activity was based on the modified method previously described [15]. Briefly, $100 \mathrm{mg}$ of rat intestinal acetone powder was homogenized in $3 \mathrm{ml}$ of $0.9 \% \mathrm{NaCl}$ solution. The solution was centrifuged at $12,000 \mathrm{~g}$ for $30 \mathrm{~min}$ and then subjected to assay. The crude enzyme solution (as maltase assay, $10 \mu \mathrm{l}$; as sucrase assay, $30 \mu \mathrm{l}$ ) was incubated with $30 \mu \mathrm{l}$ maltose $(86 \mathrm{mM})$ or $40 \mu \mathrm{l}$ sucrose (400 mM), $10 \mu \mathrm{l}$ of the extract at various concentrations, followed by the addition of $0.1 \mathrm{M}$ phosphate buffer, $\mathrm{pH} 6.9$ to give a final volume of $100 \mu \mathrm{l}$. The reaction was incubated at $37^{\circ} \mathrm{C}$ for $30 \mathrm{~min}$ (maltase assay) or 60 min (Sucrase assay). Thereafter, the mixtures were suspended in boiling water for $10 \mathrm{~min}$ to stop the reaction. The concentrations of glucose released from the reaction mixtures was determined by glucose oxidase method with absorbance at a wavelength of $450 \mathrm{~nm}$. Intestinal $\alpha$-glucosidase inhibitory activity was expressed as percentage inhibition using the following formula. Acrabose was used as positive control.

$$
\% \text { Inhibition }=\frac{\text { AbsControl-AbsSample }}{\text { AbsControl }} \times 100
$$

Where Abs Control was the absorbance without sample, Abs samples was the absorbance of sample extract.

\section{Pancreatic cholesterol esterase inhibition}

The pancreatic cholesterol esterase inhibition was performed spectrophotometrically based on previous method [13]. The extract was incubated with mixtures containing $5.16 \mathrm{mM}$ taurocholic acid, $0.2 \mathrm{mM}$ p-NPB in $100 \mathrm{mM}$ sodium phosphate buffer, $100 \mathrm{mM} \mathrm{NaCl}, \mathrm{pH}$ 7.0. The reaction was initiated by adding porcine pancreatic cholesterol esterase $(1 \mu \mathrm{g} / \mathrm{ml})$. After incubation for $5 \mathrm{~min}$ at $25^{\circ} \mathrm{C}$, the mixtures were measured the absorbance at $405 \mathrm{~nm}$. Simvastatin was used as positive control.

$$
\% \text { Inhibition }=\frac{\text { AbsControl-AbsSample }}{\text { AbsControl }} \times 100
$$

Where Abs Control was the absorbance without sample, Abs samples was the absorbance of sample extract.

\section{Pancreatic lipase inhibition}

The pancreatic lipase inhibition was performed spectrophotometrically based on previous method with little modification [16]. The extract was incubated with mixtures containing $5 \mathrm{mM}$ deoxytaurocholic acid, $0.2 \mathrm{mM}$ p-NPP in $50 \mathrm{mM}$ sodium phosphate monobasic buffer, $\mathrm{pH}$ 8.0. The reaction was initiated by adding porcine pancreatic lipase $(10 \mathrm{mg} / \mathrm{ml})$. After incubation for $5 \mathrm{~min}$ at $37^{\circ} \mathrm{C}$, the mixtures were measured the absorbance at $410 \mathrm{~nm}$. Orlistat was used as positive control.

$$
\% \text { Inhibition }=\frac{\text { AbsControl-AbsSample }}{\text { AbsControl }} \times 100
$$

Where Abs Control was the absorbance without sample, Abs samples was the absorbance of sample extract.

\section{Data analysis}

The IC50 values were calculated from plots of log concentration of inhibitor concentration versus percentage inhibition curves using sigma plot version11. The data were expressed as mean \pm standard error of mean (SEM).

\section{Results}

The amount of total flavonoids, total polyphenolic compounds, and condensed tannins contents determined in the extract are summarized in Table 1. The content of flavonoid in the extract was $71.73 \pm 2.48 \mathrm{mg}$ quercetin equivalent/g of crude extract. The total polyphenolic compound in the extract was $79.81 \pm 2.85 \mathrm{mg}$ of gallic 
Table 1 Flavonoid, total phenolic, and condensed tannin contents of Moringa stenopetala leaves extract

\begin{tabular}{lccr}
\hline & \multicolumn{3}{c}{ Phytochemical analysis } \\
\hline & Flavonoid (mg/g extract) & Total phenolics (mg/g extract) & Condensed tannins (mg/g extract) \\
\hline Moringa stenopetala & $71.73 \pm 2.48$ & $79.81 \pm 2.85$ & $8.82 \pm 0.77$
\end{tabular}

Results are expressed as means \pm S.E.M., $\mathrm{n}=3$.

acid equivalent/g of crude extract. Furthermore, the content of condensed tannins in the extract was found to be $8.82 \pm 0.77 \mathrm{mg}$ catechin equivalent/g of crude extract.

As shown in Table 2, the IC50 value of the extract was $1.47 \pm 0.19 \mathrm{mg} / \mathrm{ml}$ for intestinal sucrase, where as the extract $(5 \mathrm{mg} / \mathrm{ml})$ inhibited intestinal maltase by $48.64 \pm$ $1.18 \%$. The findings indicated that the extract was a more specific inhibitor of intestinal sucrase than intestinal maltase. The extract also inhibited pancreatic cholesterol esterase activity $(49.22 \pm 2.34)$ more than pancreatic $\alpha$-amylase $(6.06 \pm 0.75 \%)$. Moreover, it was found that the extract inhibited pancreatic lipase with IC50 value of greater than $5 \mathrm{mg} / \mathrm{ml}$.

\section{Discussion}

Diabetes mellitus is a metabolic disorder that usually affects carbohydrate, fat, and protein metabolism, followed by multiorgan injury in the later period, and hyperipidemia is associated with hyperglycemia [17]. More powerful new compounds with pan-target activity and proven long-term safety should be highly effective in a clinical setting for patients with coexisting relevant lipid and glucose metabolic disorders. These discoveries pave the way for the development of drugs for treating chronic multigenic metabolic and cardiovascular diseases, for which therapy is presently insufficient or nonexistent [18]. This is the first study to investigate the effect of leaf extract of Moringa stenopetala on pancreatic and intestinal enzymes related to antihyperglycemic and antihyperlipidemic actvities.

The presence of phytochemicals in plant products gives a great potential for balancing metabolic disturbances. Several phytomolecules including flavonoids, phenolic compounds, alkaloids, glycosides, saponins, glycolipids, dietary fibres, polysaccharides, peptidoglycans, carbohydrates, amino acids and others obtained from various plant sources have been reported as potent hypoglycemic agents. Flavonoids are a heterogeneous group of ubiquitous plant polyphenols, which exhibit a variety of pharmacological activities, including the anti-atherogenic as well as antihyperglycemic effects, lipoprotein oxidation, blood platelet aggregation and vascular reactivity [19]. A high content of phytochemicals especially total polyphenolic compounds and total flavonoids may contribute to the pleiotropic effects of Moringa stenopetala leaves that support the use of the plant for different metabolic disorders in the local community.

It is well known that inhibition of intestinal $\alpha$-glucosidase and pancreatic $\alpha$-amylase activity results in delaying carbohydrate digestion of absorbable monosaccharides, causing reduction of postprandial hyperglycemia. The plant extract showed a weaker pancreatic $\alpha$-amylase activity compared to intestinal $\alpha$-glucosidase activity. $\alpha$-glucosidase inhibitors delay intestinal carbohydrate absorption and slow the sharp rise in blood sugar levels that diabetic patients typically experience after snacks. However, none of the currently available $\alpha$-glucosidase inhibitors for clinical use are devoid of severe adverse effects [20,21]. The search for new group of agents from natural resources especially from traditional medicines has, therefore, become an attractive approach for the treatment of postprandial hyperglycemia. Our study showed that hydroalcoholic leaf extract of Moringa stenopetala is a potent inhibitor of $\alpha$-glucosidase activity, and therefore suggests that extracts of Moringa stenopetala could be an attractive source of alternative treatment.

Besides hyperglycemia, diabetes mellitus is highly characterized by elevated levels of triglycerides and cholesterol in the blood highly associated with a modern lifestyle and increase consumption of a high fat diet [22]. Reducing absorption of free fatty acids and free cholesterol by inhibiting pancreatic lipase and pancreatic cholesterol esterase reduces hyperlipidemia associated with diabetes mellitus $[23,24]$. In our previous findings it was reported that the plant material of Moringa stenopetala has antihyperlipidemic effects [12] which may be due to the inhibition of pancreatic lipase and pancreatic cholesterol esterase.

\section{Conclusion}

In conclusion, we demonstrate here that the inhibition of intestinal $\alpha$-glucosidase by extracts of Moringa stenopetala may contribute to antihyperglycemic activity. Extracts of

Table 2 The inhibitory effects of Moringa stenopetala leaf extract on pancreatic a-amylase, maltase, sucrase, pancreatic lipase, and pancreatic cholesterol esterase activities

\begin{tabular}{llllll}
\hline & \multicolumn{3}{c}{$I C_{50}$ values $(\mathrm{mg} / \mathrm{ml})$} \\
\hline Moringa stenopetala & Pancreatic a-Amylase & Maltase & Sucrase & Pancreatic lipase & Pancreatic cholesterol esterase \\
\hline
\end{tabular}

Results are expressed as means \pm S.E.M., $\mathrm{n}=3$. 
Moringa stenopetala also show antihyperlipidemic activity due to the inhibition of lipase and cholesterol esterase enzymes. Thus plant material of Moringa stenopetala could be used for prevention/treatment of hyperglycemia and hyperlipidemia. Further illustration on mechanism(s) of Moringa stenopetala leaves on insulin secretion and plasma lipid inhibition on animal models, and role of the plant material for management of protein glycation are being investigated.

\section{Competing interests}

The authors declare that they have no competing interests.

\section{Authors' contribution}

AT conceived the idea, drafted the proposal and involved in all implementation stages of the project and write up. EM, YM, AD and SA reviewed the proposal, and involved in all implementation stages of the project and write up. All authors reviewed the proposal and the final manuscript. All authors approved final version of the manuscript.

\section{Acknowledgments}

We would like to thank Addis Ababa University, Hawassa University, Chulalongkorn University and Ethiopian Health and Nutrition Research Institute for funding this research. We also like to appreciate technical assistance of Mr. Berhanu Tesfaye, Mr Bekesho Geleta, Mr Weerachat Sompong and Mrs Thavaree Thilavech during laboratory work. The corresponding author would like to express his heartfelt gratitude to Dr. Andrew Beale for editing the language in the manuscript.

\section{Author details}

${ }^{1}$ Pharmacology Department, School of Medicine, Addis Ababa University, Addis Ababa, Ethiopia. ${ }^{2}$ Pharmacology Unit, School of Medicine, Hawassa University, P O Box 1560, Hawassa, Ethiopia. ${ }^{3}$ Department of Biology, College of Natural Sciences, Addis Ababa University, Addis Ababa, Ethiopia. ${ }^{4}$ Department of Traditional and Modern Drug Research, Ethiopian Public Health Institute (EHPI), Addis Ababa, Ethiopia. ${ }^{5}$ The Medical Food Research and Development Center, Department of Nutrition and Dietetics, Faculty of Allied Health Sciences, Chulalongkorn University, Pathumwan 10330 Bangkok, Thailand.

Received: 3 January 2014 Accepted: 29 May 2014

Published: 3 June 2014

\section{References}

1. Wild S, Roglic G, Green A, Sicree R, King H: Global prevalence of diabetes. Diabetes Care 2004, 27:1047-1053.

2. International Diabetes Federation Atlas. 6th edition; 2013. http://www.idf.org/ diabetesatlas/downloaded in 30/11/2013.

3. Levin M, Pfeifer M: Uncomplicated Guide to Diabetes Complications. 3rd edition. Alexandria, Virginia: American Diabetes Association; 2009.

4. Edwards S, Tadesse M, Demissew S, Hedberg J: Flora of Ethiopia and Eritrea: mangnoliaceae to flacourtiacea, the national herbarium. Ethiopia 2002, 1:155-163.

5. Mekonnen Y, Gessesse A: Documentation on the use of Moringa Stenopetala and its possible antileshimanial and antifertility effects. SINET: Ethiopian J SCi 1998, 21:287-295.

6. Mengistu M, Abebe $\mathrm{Y}$, Mekonnen $\mathrm{Y}$, Tolessa T: Invivo and invitro hypotensive effect of aqueous extract of Moringa stenopetala leaves. Afr Health Sci 2012, 12(4):445-451.

7. Mekonnen Y, Yardely V, Rock P, Croft S: In vitro antitrypanosomal activity of Moringa Stenopetala leaves and roots. Phytother Res 1999, 13:538-539.

8. Mekonnen Y: Effects of ethanol extracts of Moringa Stenopetala leave on guinea pig and mouse smooth muscle. Phytother Res 1999, 13:442-444.

9. Makonnen E, Hunde A, Damecha G: Hypoglycemic effect of Moringa Stenopetala aqueous extracts in Rabbits. Phytother Res 1997, 11:147-148.

10. Mussa A, Makonnen E, Urga K: Effects of the crude aqueous extract and isolated fraction of moringa stenopetala leaves in normal and diabetic mice. Pharmacologyonline 2008, 3:1049-1055.
11. Nardos A, Makonnen E, Debella A: Effects of crude extracts and fractions of Moringa stenopetala (Baker f) Cufodontis leaves in normoglycemic and alloxan-induced diabetic mice. Afr J Pharm Pharmacol 2011, 5:2220-2225.

12. Toma A, Makonnen E, Debella A, Tesfaye B: Antihyperglycemic effect on chronic administration of butanol fraction of ethanol extract of moringa stenopetala leaves in alloxan induced diabetic mice. Asian Pac J Trop Biomed 2012, 2:S1606-S1610.

13. Adisakwattana S, Chanathong B: a-glucosidase inhibitory activity and lipid-lowering mechanisms of Moringa oleifera leaf extract. Eur Rev Med Pharmacol Sci 2011, 15:803-808.

14. Mishra J, Yousuf A, Singh D, Aradhana A: Phytochemical investigation and in-vitro antioxidant potential of leaves of Murraya koengii. Int J Integr Biol 2009, 7:171-174.

15. Adisakwattana S, Ruengsamran T, Kampa P, Sompong W: Invitro inhibitory effects of plant-based foods and their combinations on intestinal a-glucosidase and pancreatic a-amylase. BMC Complement Altern Med 2012, 12:110.

16. Lewis D, Liu D: Direct measurement of lipase inhibition by orlistat using dissolution linked in vitro assay. Clinic Pharmacol Biopharm 2012, 1:103. doi:10.4172/2167-065X.1000103.

17. Upendra M, Sreenivasulu M, Chengaiah B: Micro-vascular and macrovascular complication of diabetes mellitus. IJPRIF 2010, 2:1883-1892.

18. Toma A: Recent advances on novel dual-acting peroxisome proliferatoractivated receptor alpha and gamma agonists. Int J Pharm Sci Res 2013, 4:1644-1653.

19. Mukherjee $P$, Maiti $K$, Mukherjee $K$, Houghton P: Leads from Indian medicinal plants with hypoglycemic potentials. J Ethnopharmacol 2006, 106:1-28.

20. Kurihara $\mathrm{H}$, Ando J, Hatano M, Kawabata J: Sulfoquinovosyldacylglycerolas alpha glucosidase inhibitor. Bioorg Med chemlett 2011, 5:1241-1244.

21. Sama K, Murugesan K, Sivaraj R: Invitro alpha amylase and alpha glucosidase inhibition activity of crude ethanol extract of Cissus arnottiana. Asian J Plant Sci Res 2012, 4:550-553.

22. Jacobson T, Miller M, Schaefer E: Hypertriglyceridemia and cardiovascular risk reduction. Clin Ther 2007, 29:763-777.

23. Birari $R$, Bhutani $K$ : Pancreatic lipase inhibitors from natural sources: unexplored potential. Drug Discov Today 2007, 12:879-889.

24. Heidrich J, Contos L, Hunsaker L, Deck M, Vander D: Inhibition of pancreatic cholesterol esterase reduces cholesterol absorption in the hamster. BMC Pharmacol 2004, 4:5-9.

doi:10.1186/1472-6882-14-180

Cite this article as: Toma et al.: Intestinal $a$-glucosidase and some pancreatic enzymes inhibitory effect of hydroalcholic extract of Moringa stenopetala leaves. BMC Complementary and Alternative Medicine 2014 14:180

\section{Submit your next manuscript to BioMed Central and take full advantage of:}

- Convenient online submission

- Thorough peer review

- No space constraints or color figure charges

- Immediate publication on acceptance

- Inclusion in PubMed, CAS, Scopus and Google Scholar

- Research which is freely available for redistribution 